Supplement of Nat. Hazards Earth Syst. Sci., 21, 2257-2276, 2021

https://doi.org/10.5194/nhess-21-2257-2021-supplement

(C) Author(s) 2021. CC BY 4.0 License.

(c) (1)

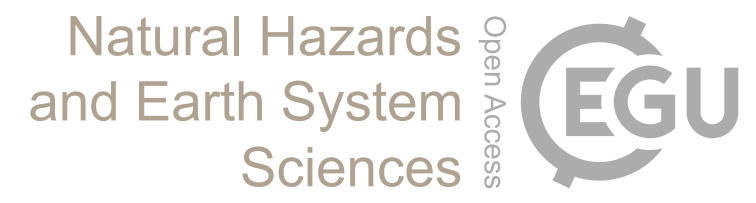

Supplement of

\title{
Deep uncertainties in shoreline change projections: an extra-probabilistic approach applied to sandy beaches
}

Rémi Thiéblemont et al.

Correspondence to: Rémi Thiéblemont (r.thieblemont@brgm.fr)

The copyright of individual parts of the supplement might differ from the article licence. 


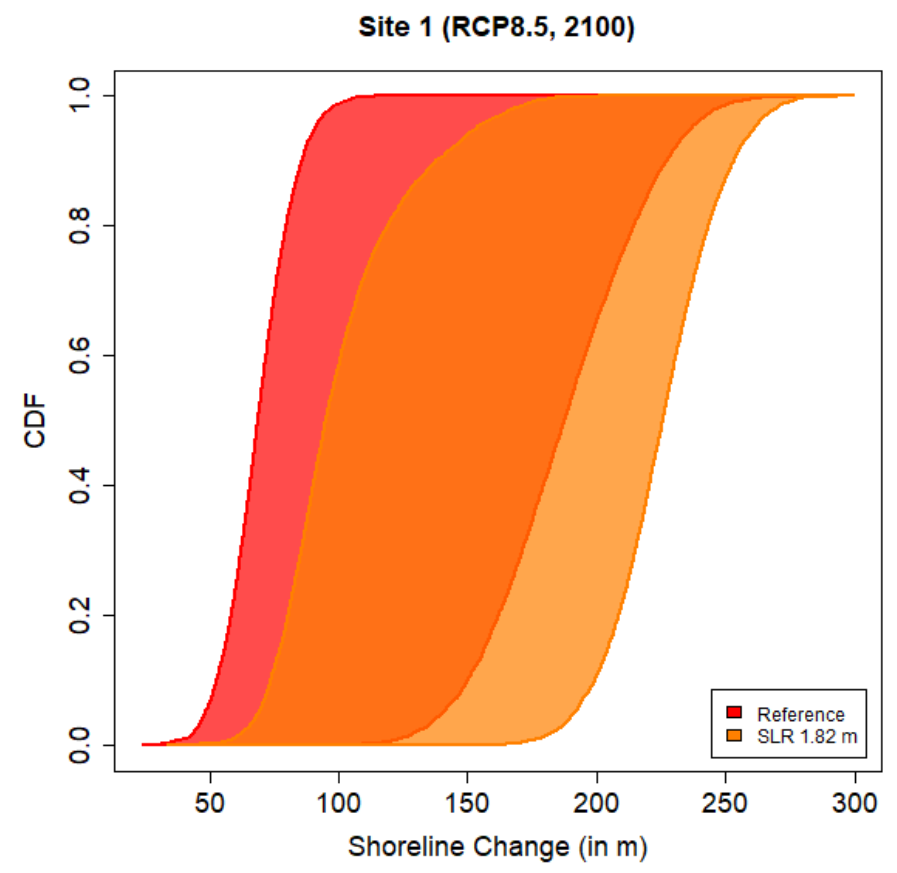

Figure S1. Projected shoreline change probability boxes in 2100 in Aquitaine under the RCP8.5 scenario when (red) considering the full SLR possibility distribution or (orange) fixing the SLR to a high-end value (i.e. $1.82 \mathrm{~m}$ ).

a)

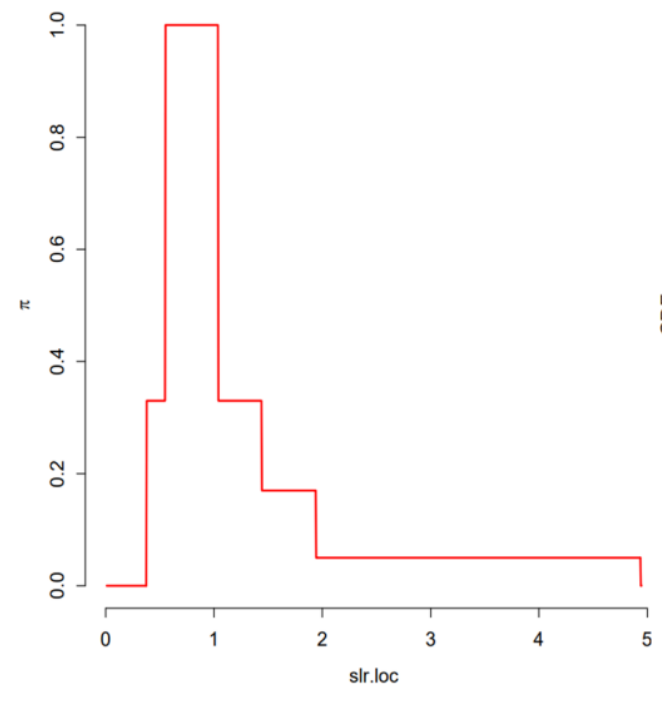

b)

Aquitaine 2100 (RCP8.5)

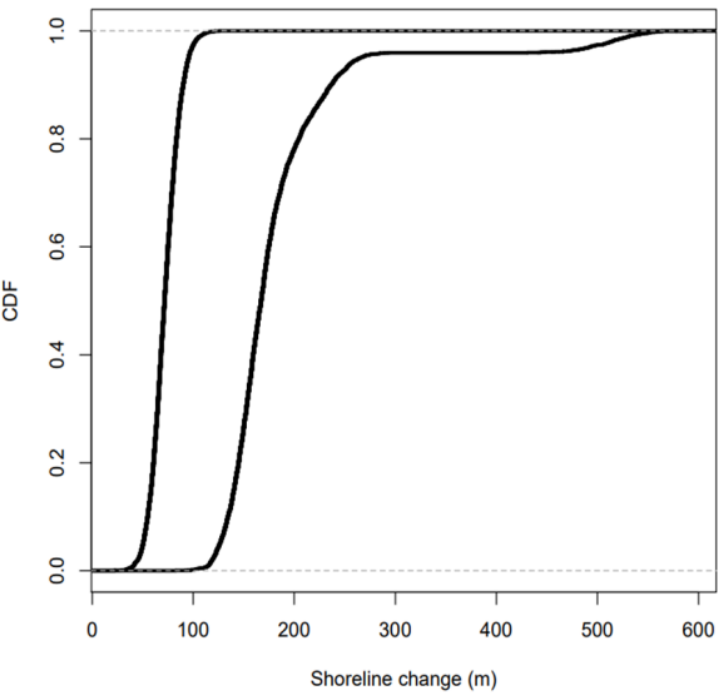

Figure S2. (b) Projected shoreline change probability box by 2100 for Aquitaine under the RCP8.5 scenario, by including (a) multiple global mean sea-level high-end projections prescribed through a possibility distribution consistent with the review of Le Cozannet et al. (2017). 